\title{
Gas Phase Chemistry of Trimethylboron in Thermal Chemical Vapor Deposition
}

\author{
Mewlude Imam, ${ }^{\dagger}$, Laurent Souqui, $^{\dagger}$ Jan Herritsch, $^{\S}$ Andreas Stegmüller, ${ }^{\S}$ Carina Höglund, ${ }^{\dagger,}$ \\ Susann Schmidt, ${ }^{\dagger}$ Richard Hall-Wilton, ${ }^{\ddagger}, \| \odot$ Hans Högberg, ${ }^{\dagger}$ Jens Birch, ${ }^{\dagger} \odot$ Ralf Tonner, ${ }^{\S \odot}$ \\ and Henrik Pedersen* ${ }^{*} \dagger$ \\ ${ }^{\dagger}$ Department of Physics, Chemistry and Biology, Linköping University, SE-581 83 Linköping, Sweden \\ ${ }^{\ddagger}$ European Spallation Source ERIC, P.O. Box 176, SE-221 00 Lund, Sweden \\ ${ }^{\S}$ Fachbereich Chemie and Material Sciences Center, Philipps-Universität Marburg, Hans-Meerwein-Strasse 4, D-35032 Marburg, \\ Germany \\ "Mid-Sweden University, SE-85170 Sundsvall, Sweden
}

Supporting Information

\begin{abstract}
Alkylboranes, such as trimethylboron (TMB) and triethylboron (TEB), are promising alternative precursors in lowtemperature chemical vapor deposition (CVD) of boron-containing thin films. In this study, CVD growth of B-C films using TMB and quantum-chemical calculations to elucidate a gas phase chemical mechanism were undertaken. Dense, amorphous, boron-rich $(\mathrm{B} / \mathrm{C}=$ 1.5-3) films were deposited at $1000{ }^{\circ} \mathrm{C}$ in both dihydrogen and argon ambients, while films with crystalline $\mathrm{B}_{4} \mathrm{C}$ and $\mathrm{B}_{25} \mathrm{C}$ inclusions were deposited at $1100{ }^{\circ} \mathrm{C}$ in dihydrogen. A script-based automatization scheme was implemented for the quantum-chemical computations to enable time efficient screening of thousands of possible gas phase CVD reactions. The quantum-chemical calculations suggest TMB is mainly decomposed by an unimolecular $\alpha$-H elimination of methane, which is complemented by dihydrogen-assisted elimination of methane in dihydrogen.

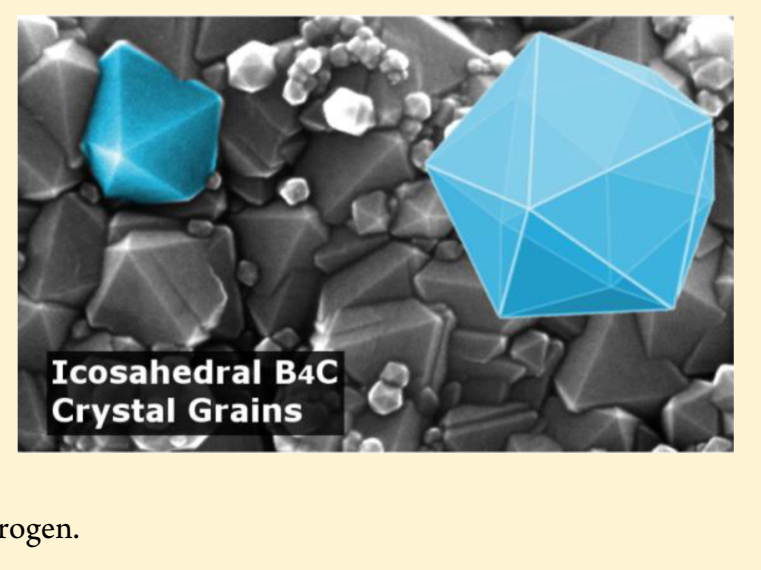

\section{INTRODUCTION}

Thin film synthesis of boron-containing materials, especially carbides $\left(\mathrm{B}_{4} \mathrm{C}\right)$, nitrides $(\mathrm{BN})$, and metal borides (e.g., $\left.\mathrm{TiB}_{2}\right)$, have been studied by chemical vapor deposition (CVD) methods using boron halides and hydrides as boron precursors in a hydrogen ambient. ${ }^{1-9}$ Boron hydrides, mainly diborane $\left(\mathrm{B}_{2} \mathrm{H}_{6}\right)$, have been widely used for semiconductor applications as they require lower deposition temperatures and provide films with a low level of contamination. However, diborane is highly toxic and explosive, making its handling and storing troublesome. Alternatively, boron halides, predominantly boron trichloride $\left(\mathrm{BCl}_{3}\right)$ and boron tribromide $\left(\mathrm{BBr}_{3}\right)$, have been favored by the hard-coatings industry where higher $\mathrm{CVD}$ temperatures are used and lower requirements on film impurities are set. Compared to diborane, boron halides are less problematic to handle but are not considered suitable for film deposition on metallic substrates due to the formation of hydrogen halides such as $\mathrm{HCl}$. Additionally, $\mathrm{BCl}_{3}$ requires high deposition temperatures making it incompatible for CVD of boron-based thin films on temperature-sensitive substrates.

Alkylboranes, such as trimethylboron (TMB), $\mathrm{B}\left(\mathrm{CH}_{3}\right)_{3}$, triethylboron (TEB), $\mathrm{B}\left(\mathrm{C}_{2} \mathrm{H}_{5}\right)_{3}$, and tributylboron (TBB), $\mathrm{B}\left(\mathrm{C}_{4} \mathrm{H}_{9}\right)_{3}$, have been suggested as highly reactive, nonpoisonous, nonexplosive alternative B-precursors. ${ }^{10}$ These alkylboranes were tested as single-source precursors in CVD of $\mathrm{B}-\mathrm{C}$ films, and TEB was found to be the best-suited, resulting in $\mathrm{B} / \mathrm{C}$ ratios between 0.1 and 1.6. TMB and TBB were deemed not suitable as CVD precursors since no boron was found in the films deposited from these molecules. ${ }^{10}$ Since then, extensive CVD studies have been undertaken on TEB for crystalline $\mathrm{sp}^{2}-\mathrm{BN}$ films ${ }^{11}$ and boron-carbon $\left(\mathrm{B}_{x} \mathrm{C}\right)^{12,13}$ thin films. Using the combination of $\mathrm{B}-\mathrm{C}$ film deposition and quantum-chemical computations, a gas phase chemical mechanism based on $\beta$-hydride elimination of ethane and dihydrogen-assisted elimination of ethane has been suggested for TEB. ${ }^{13}$ Although TMB was found unsuitable in thermal $\mathrm{CVD},{ }^{10}$ we recently applied it as single-source precursor together with argon plasma CVD for the deposition of $\mathrm{B}-\mathrm{C}$ films. ${ }^{14}$ Here, the $\mathrm{B} / \mathrm{C}$ ratio of the deposited films ranged between 0.4 and 1.9 with a hydrogen content of $10-20$ at. \%. A plasma chemical model was proposed in which the methyl groups of TMB are first dehydrogenated, likely by argon radicals and thermal energy, followed by $\mathrm{B}-\mathrm{C}$ bond cleavage to form $\mathrm{BH}$ and $\mathrm{CH}$ radicals. The $\mathrm{CH}$ radicals then combine to

Received: September 26, 2017

Revised: October 27, 2017

Published: November 13, 2017 
form dicarbon. $\mathrm{BH}, \mathrm{CH}$, and $\mathrm{C}_{2}$ were suggested as the main film-forming species in the plasma.

Herein, we seek to understand the gas phase chemistry of $\mathrm{TMB}$ in a thermal CVD process. Our approach is a combination of B-C film deposition experiments at 700$1100{ }^{\circ} \mathrm{C}$ in both hydrogen and argon atmospheres while using quantum-chemical calculations to investigate a wide range of possible gas phase reactions. As quantum-chemical calculations of gas phase decomposition chemistry in CVD processes rely on time-consuming manual selection of fragments, input generation, output, and thermodynamic analysis, ${ }^{13,15,16}$ we have taken inspiration from various elaborate automatization schemes proposed in other contexts, such as the simulation of mass spectra ${ }^{7,18}$ and screening for electrolyte materials. ${ }^{19}$ Here, we present and apply a simple script-based automatization procedure that was tailored and implemented for CVD gas phase chemistry investigations. Based on the combination of experimental and theoretical results, a possible gas phase chemical model for TMB at CVD conditions is suggested.

\section{METHODS}

Film Deposition. The boron-carbon films were deposited in a horizontal hot-wall CVD (base pressure $4 \times 10^{-7} \mathrm{mbar}$ ) reactor using TMB as single-source precursor. The deposition temperatures ranging from 700 to $1100{ }^{\circ} \mathrm{C}$ were monitored by a pyrometer pointing into a hole drilled into the $\mathrm{SiC}$-coated graphite susceptor. For each experiment, $1.4 \mathrm{sccm}$ TMB (99.5\%, Voltaix/Air Liquide Advanced Materials) was diluted in $2000 \mathrm{sccm}$ of either argon (99.9997\%) or dihydrogen (purified by a palladium membrane). The pressure was maintained at 5.0 $\mathrm{kPa}(50 \mathrm{mbar})$ by a throttle valve on the process pump. Singlecrystal (100)-oriented silicon substrates were used in all depositions. Prior to deposition, the substrates were cleaned successively in an acetone ultrasonic bath and isopropyl alcohol and then blow-dried with nitrogen gas.

Film Characterization. Scanning electron microscopy (SEM), using a LEO 1550 Gemini SEM equipped with a field emission gun (FEG), was used to measure the film thickness. The deposition rate was calculated by dividing the film thickness with the deposition time. The relative amounts of contained elements were obtained by time-of-flight elastic recoil detection analysis (ToF-ERDA) using $36 \mathrm{MeV}$ iodine ions and incidence and acceptance angle at $67.5^{\circ}$. The chemical composition and bonding states of the films were investigated by X-ray photoelectron spectroscopy (XPS, Axis UltraDLD, Kratos Analytical, Manchester, U.K.) using monochromatic aluminum $(\mathrm{K} \alpha) \mathrm{X}$-ray radiation $(h \nu=1486.6 \mathrm{eV})$. XPS survey spectra and core level spectra of the B 1s, Ar 2p, C 1s, and O 1s regions were recorded both for as-deposited samples and after sputter cleaning using a sequence of $\mathrm{Ar}^{+}$ions with $2 \mathrm{kV}$ for 180 $\mathrm{s}$ and then $0.5 \mathrm{kV}$ for $180 \mathrm{~s}$. To assess the bonding configuration of the $\mathrm{B}_{x} \mathrm{C}$ films, the core level spectra were deconvoluted using a Voigt peak shape with a Lorentzian contribution of $30 \%$. The structural properties of the films were investigated by XRD in a Bragg-Brentano configuration using $\mathrm{Cu}-\mathrm{K} \alpha$ radiation with a Bragg-Brentano $\mathrm{HD}$ mirror with $0.5^{\circ}$ divergence and antiscatter slits on the primary side and X'celerator detector operating in a scanning line mode with 5.0 $\mathrm{mm}$ antiscatter slits and $\mathrm{Ni}$ filter on the secondary side. X-ray reflectivity measurements of films were carried out using a Philips X'Pert Pro MRD diffractometer equipped with a hybrid mirror monochromator and parallel plate collimator as primary and secondary optics, respectively. Film densities were determined by fitting the XRR data using X'pert reflectivity software.

Quantum Chemical Calculations. The molecular structures investigated were optimized on the density functional theory (DFT) level using the GGA functional $\mathrm{PBE}^{20}$ and the def2-TZVPP ${ }^{21}$ basis set. Transition states (TS) were searched by a quadratic-synchronous transit method and verified by intrinsic reaction path. ${ }^{22,23}$ Identification of minima (no imaginary frequencies), TS (one imaginary frequency), and derivation of thermodynamic properties were achieved by calculations of the Hessian. While "tight" convergence criteria were used for the structural optimization in the screening of reactions in the automatic search outlined below, "very tight" criteria was used for transition state search and connected minima. All results discussed in the main text were derived with the stricter convergence criteria. All closed-shell molecules were investigated in singlet and triplet states, while all radicals were calculated in doublet and quartet states. The thermodynamic corrections were computed at $T=400,800$, and $1200{ }^{\circ} \mathrm{C}$ and $p$ $=5 \mathrm{kPa}(50 \mathrm{mbar})$. These settings represent typical CVD reactor conditions. Entropy corrections are sensitive to even small errors in the low-frequency vibrations of the molecule. Thus, absolute Gibbs energies at high temperatures must be interpreted with care, but trends are much less sensitive to this issue. Calculations were performed with Gaussian09. ${ }^{24}$

Automatic Search for Decomposition Reactions of Reactants. The scheme intends to identify all possible decomposition products that can be reached in a sequence of elementary reactions including all intermediate products in a combinatorial approach. Species are selected via predefined rules representing chemical character and stability (e.g., allowing diradicals). Based on the thermodynamic data of reaction conditions $(\Delta G)$, a reaction network was formulated. Applying this scheme to TMB resulted in 79 decomposition products and 13940 reaction equations of which 1100 are unimolecular reactions. More details and the full list of reactions are found in the Supporting Information section SI-2.

\section{RESULTS AND DISCUSSION}

The appearance of the deposited films changed within a color gradient of black-gray-pale gray when the deposition temperature was increased from 700 to $1100{ }^{\circ} \mathrm{C}$ in both dihydrogen and argon atmospheres. The films deposited at low temperatures look smooth and shiny while films deposited above $900{ }^{\circ} \mathrm{C}$ appeared rougher, especially when deposited in argon. The $\mathrm{B}-\mathrm{C}$ films deposited at $1000{ }^{\circ} \mathrm{C}$ and above were severely bent due to residual film stress and were visible to the naked eye. This was most pronounced for films grown in an $\mathrm{Ar}$ atmosphere. Cross-sectional SEM images (Figure 1) showed the morphology of the $\mathrm{B}-\mathrm{C}$ films to be dependent on the deposition atmosphere and temperature. Films deposited in dihydrogen atmosphere appeared comparatively dense and smooth without features while films deposited in argon showed some fine features. The difference in morphology can be attributed to the different film composition and density (see Figure SI-1). All films were adherent on silicon substrates, and an interface reaction between substrate and film was observed for depositions at $\geq 1000{ }^{\circ} \mathrm{C}$, similar to that previously reported for CVD of $\mathrm{B}_{x} \mathrm{C}$ thin films from TEB. ${ }^{13}$

The film deposition rate showed a strong dependence on the deposition temperature as shown in Figure 2. It is most significant in an argon atmosphere where the deposition rate increased with the temperature throughout the studied range. 


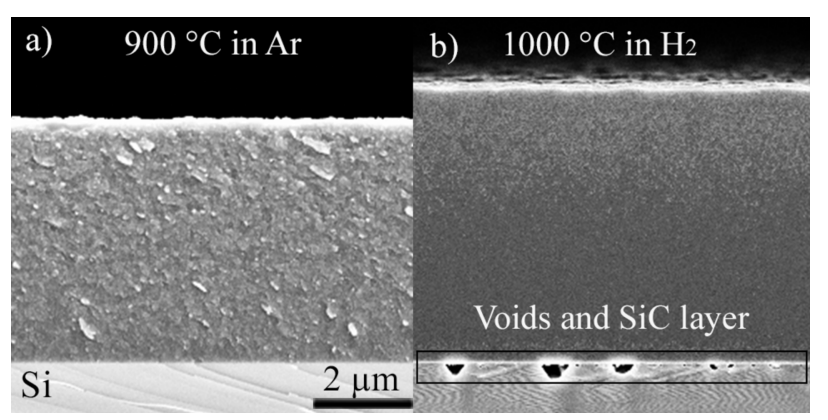

Figure 1. Cross-sectional SEM images of films deposited at (a) $900{ }^{\circ} \mathrm{C}$ in argon and (b) $1000{ }^{\circ} \mathrm{C}$ in dihydrogen atmosphere; $\mathrm{SiC}$ layer formed at the interface and voids in the substrate.

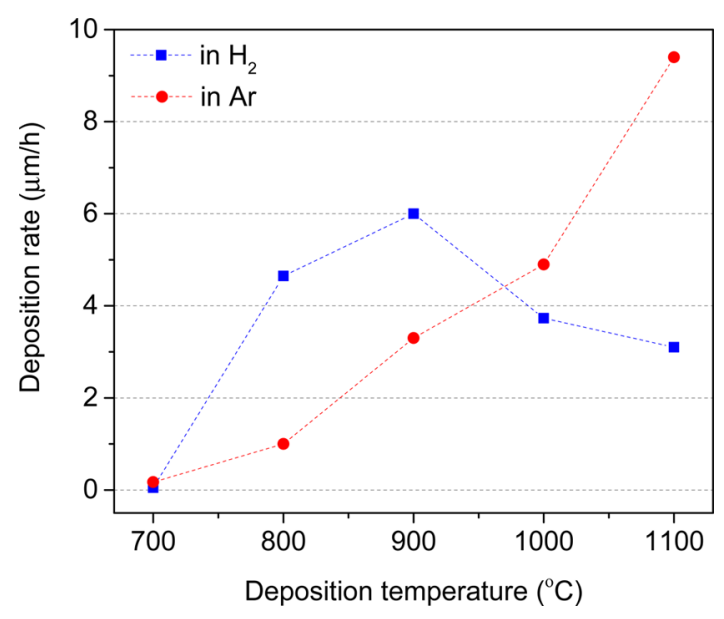

Figure 2. Deposition rates in dihydrogen (squares) and argon (circles) atmospheres as a function of deposition temperature.

In a dihydrogen atmosphere, the deposition rate increased with the temperature up to $900{ }^{\circ} \mathrm{C}$ while at temperatures above 900 ${ }^{\circ} \mathrm{C}$ it decreased. For temperatures below $700{ }^{\circ} \mathrm{C}$, only very thin films in the tens of nanometer range were deposited in both dihydrogen and argon atmospheres. The plotted disposition rates in Figure 2 show that the argon atmosphere seemingly follows one slope, while in the dihydrogen atmosphere there are two slopes: one above and below $900{ }^{\circ} \mathrm{C}$. In classical CVD theory, the deposition rate plotted against the inverse temperature can be seen to follow an Arrhenius equation, and temperature regions where the deposition is limited by kinetics, mass transport, or thermodynamics can be identified. The two slopes for deposition in dihydrogen suggest that a shift from kinetics or mass transport limited to thermodynamics limited occurs at around $900{ }^{\circ} \mathrm{C}$.

The elemental composition of films obtained from ToFERDA showed that they consisted of mainly boron and carbon. The quantification of hydrogen content in the films was less certain. However, it seems the increasing deposition temperature leads to lower deposition of hydrogen in the films. Other impurities such as oxygen were also decreased below 1 at. \% with increasing temperature.

The B/C ratio of the deposited films (Figure 3) was found to be both deposition temperature and deposition atmosphere dependent. An increase in deposition temperature resulted in an increased boron content of the films. The highest B/C ratios of 3 and 1.5 were obtained at $1000{ }^{\circ} \mathrm{C}$ in dihydrogen and argon atmospheres, respectively. The increasing $\mathrm{B} / \mathrm{C}$ ratio at elevated temperatures can be explained by an increased formation of

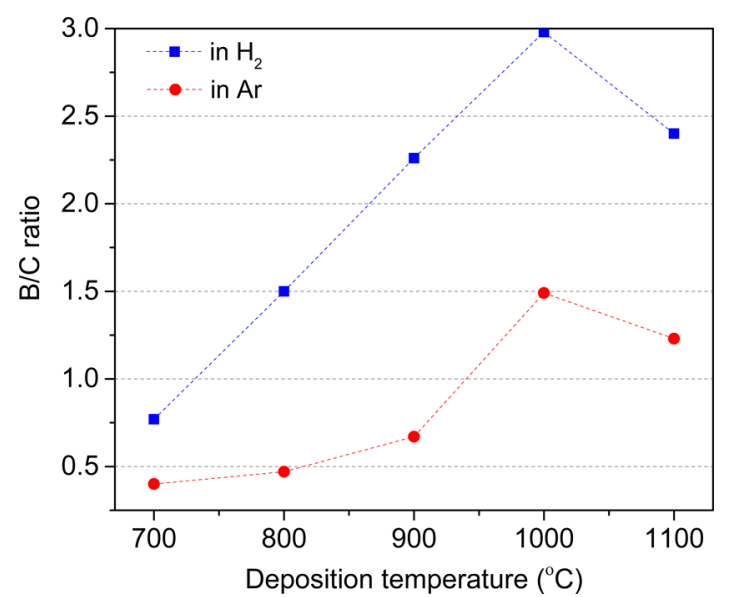

Figure 3. B/C ratio of films deposited in both dihydrogen (squares) and argon (circles) as a function of deposition temperature.

methane in a dihydrogen ambient, which makes some of the carbon on TMB molecules inactive for film deposition. Deposition atmosphere was also found to be influential for film composition. The B/C ratios of films deposited in dihydrogen are 1.5-3 times higher than that deposited in argon. This result indicates that hydrogen allows for different decomposition pathways of TMB or serves to preferentially desorb carbon from the film surface. However, at $1100{ }^{\circ} \mathrm{C}$ a slight decrease in $\mathrm{B} / \mathrm{C}$ ratio was observed for both atmospheres and can be attributed to more favorable conditions for carbon deposition at high temperatures similarly to TEB. ${ }^{13}$

All films deposited in a dihydrogen atmosphere at temperatures below $1000{ }^{\circ} \mathrm{C}$ are X-ray amorphous, while diffractograms recorded for films deposited in an argon atmosphere above $800{ }^{\circ} \mathrm{C}$ show a broad bump around the position of the 002 peak of graphite $\left(\sim 26^{\circ}\right)$ (Figure SI-2). Films deposited at $1100{ }^{\circ} \mathrm{C}$ (Figure 4) exhibit XRD peaks at $22^{\circ}$ and $37.6^{\circ}$, which are attributed to the 003 and 021 peaks of rhombohedral $\mathrm{B}_{4} \mathrm{C}$. The peak at $34.8^{\circ}$ (see inset in Figure 4) partly overlaps with a sharp peak at $35.5^{\circ}$ and is assigned as the 104 peak of $\mathrm{B}_{4} \mathrm{C}$. It should be noted that 003, 021, and 104 are common peaks for different rhombohedral boron carbides such as $\mathrm{B}_{4} \mathrm{C}, \mathrm{B}_{6.5} \mathrm{C}$, and $\mathrm{B}_{10} \mathrm{C}$, making the assignment to $\mathrm{B}_{4} \mathrm{C}$ ambiguous. The sharp

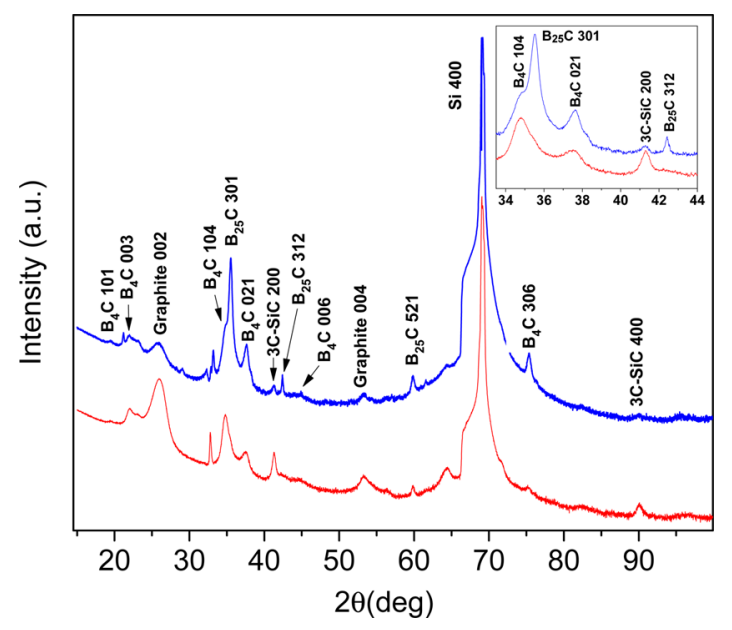

Figure 4. XRD diffractogram of films deposited at $1100{ }^{\circ} \mathrm{C}$ in both dihydrogen (top) and argon (bottom) atmospheres. The inset illustrates the scan range from $34^{\circ}$ to $44^{\circ}$. 
peak at $35.5^{\circ}$ observed for films that were deposited in dihydrogen does not fit into any rhombohedral structures. However, considering the absence of such a peak in films deposited in an argon atmosphere and the higher $\mathrm{B} / \mathrm{C}$ ratio of films deposited in dihydrogen (Figure 3), this peak can be attributed to the 301 peak of tetragonal $\mathrm{B}_{25} \mathrm{C}$. The peaks at around $42^{\circ}$ and $59.9^{\circ}$ are also assigned as 312 and 521 peaks of $\mathrm{B}_{25} \mathrm{C}$, respectively. In addition to peaks originating from boron carbides, peaks related to the silicon substrate and graphite were also observed. A peak at $41.3^{\circ}$ is attributed to the 200 peak of $3 \mathrm{C}-\mathrm{SiC}$, which is most probably from $\mathrm{SiC}$ formed on the substrate interface (Figure 1).

The plan-view SEM of the films deposited at $1100{ }^{\circ} \mathrm{C}$ for different deposition times showed an enhanced nucleation of grains, making the surface rougher compared to the amorphous films deposited below $1000{ }^{\circ} \mathrm{C}$. The SEM plan view shown in Figure $5 \mathrm{a}$ of a film deposited in dihydrogen at $1100{ }^{\circ} \mathrm{C}$ for half

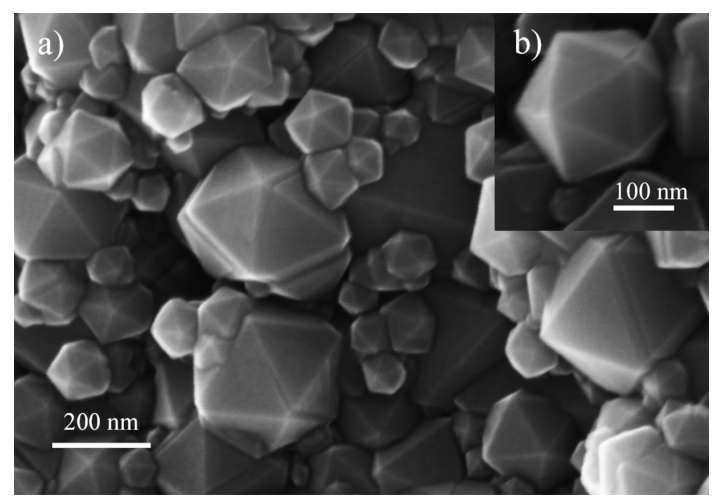

Figure 5. SEM surface micrograph of a film deposited in dihydrogen atmosphere at $1100{ }^{\circ} \mathrm{C}$ : (a) Formation of multiply twinned icosahedral $\mathrm{B}_{4} \mathrm{C}$ crystals with fivefold symmetry; (b) single icosahedral $\mathrm{B}_{4} \mathrm{C}$ crystal grain.

an hour showed very well-defined fivefold symmetry crystal grains. The XRD peaks seen in Figure 4 and the observed icosahedron-like crystal grain shown in Figure $5 \mathrm{~b}$ all supported the formation of fivefold symmetry icosahedral multiply twinned $\mathrm{B}_{4} \mathrm{C}$ crystals. ${ }^{25}$ Since XRD indicates the formation of boron-rich phases such as $\mathrm{B}_{4} \mathrm{C}$ and $\mathrm{B}_{25} \mathrm{C}$ and ERDA shows a $\mathrm{B} /$ $\mathrm{C}$ ratio of only $1.3-2.5$, it is reasonable to assume that a part of the film is amorphous.

The XPS analysis shows the B 1s spectra of films deposited in dihydrogen containing one dominant peak at a binding energy of $188.8 \pm 0.2 \mathrm{eV}$, which was assigned to $\mathrm{B}-\mathrm{C}$ bonds as shown in Figure 6a, and a minor B-O bond around 190.5-191 eV., ${ }^{4,26}$ The B 1s core level spectra for films deposited in argon at temperatures below $1000{ }^{\circ} \mathrm{C}$ show four components (not shown) of which two appeared within 190.3-192.5 eV and therefore are attributed to $\mathrm{B}-\mathrm{O}$ bonds. ${ }^{26}$ The presence of oxide-related bonds is significantly reduced for films deposited at higher temperatures, which is explained by a higher film density for deposition temperatures $>900{ }^{\circ} \mathrm{C}$ (see Figure SI-1 and Table SI-1), making the films less prone to oxygen uptake upon air exposure. For films deposited in dihydrogen and argon, the $\mathrm{B}-\mathrm{C}$ binding energy decreases by $0.1-0.3 \mathrm{eV}$ as the deposition temperature increases. This shift is associated with an extenuated effect of the nearest neighbor (secondary chemical shift) as the concentration of carbon is decreased and boron is increased in the films.
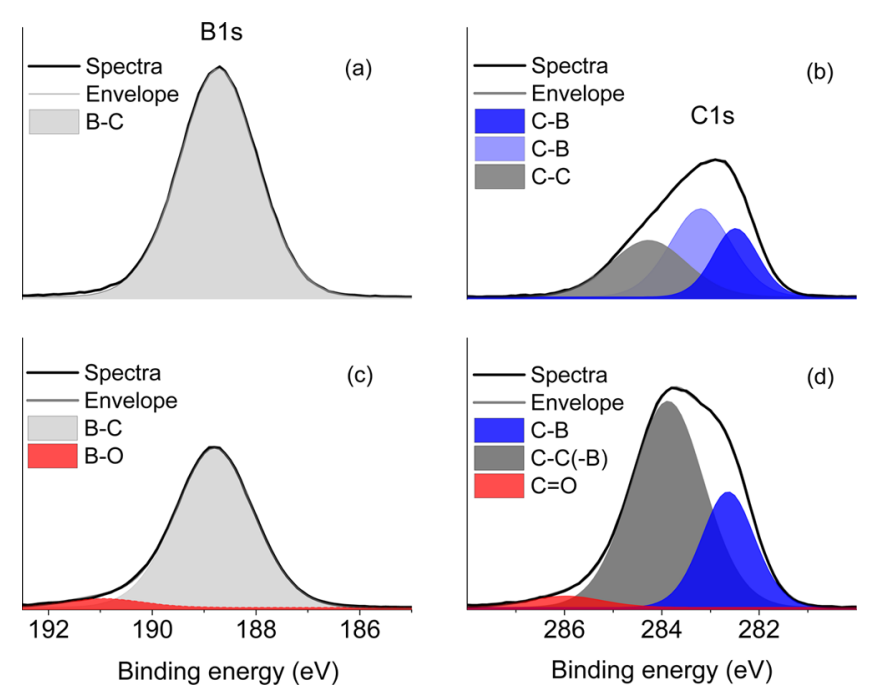

Figure 6. XPS core level spectra of B 1s (a, deposited in dihydrogen) and (c, deposited in argon), C 1s (b, deposited in dihydfogen) and (d, deposited in argon) of films deposited at $1000{ }^{\circ} \mathrm{C}$.

The C 1s spectra of films deposited in dihydrogen are fitted with two components, showing binding energies at $282.6 \pm 0.1$ and $283.5 \pm 0.3 \mathrm{eV}$ (Figure $6 \mathrm{~b}$ ), which are very close to $\mathrm{C}-\mathrm{B}$ bonds in the $\mathrm{C}-\mathrm{B}-\mathrm{C}$ chain and in the icosahedra, respectively. ${ }^{26} \mathrm{~A}$ third contribution in the $\mathrm{C} 1 \mathrm{~s}$ spectra is observed at $284.3 \mathrm{eV}$ when films are deposited at $1000{ }^{\circ} \mathrm{C}$, indicating the formation of graphitic carbon. The $\mathrm{C} 1 \mathrm{~s}$ spectra for films deposited in argon (Figure 6d) are also fitted with three components that are assigned to $\mathrm{C}-\mathrm{B}$ at $282.8 \pm 0.2 \mathrm{eV}$, $\mathrm{C}-\mathrm{C}(-\mathrm{B})$ at $283.9 \pm 0.1 \mathrm{eV}$, and $\mathrm{C}=\mathrm{O}$ at $285.5 \pm 0.5 \mathrm{eV}$ bonds. ${ }^{26}$ The high intensity and binding energy of the C$\mathrm{C}(-\mathrm{B})$ bonds at $\sim 284 \mathrm{eV}$ for films deposited in argon compared to the binding energies of $\mathrm{C}-\mathrm{B}-\mathrm{C}$ bonds for films deposited in dihydrogen are consistent with the lower $\mathrm{B} / \mathrm{C}$ ratios in films deposited in argon (Figure 3). This is attributed to the replacement of $\mathrm{B}$ atoms by $\mathrm{C}$ atoms in the films deposited using argon.

Quantum Chemical Investigations. We applied the script-based automatization procedure to investigate a large number of possible reactions in the gas phase decomposition of TMB with quantum-chemical methods. The resulting reaction energies and Gibbs energies at various temperatures allow the identification of the most probable reactions. We mimicked the experimental CVD conditions by allowing only unimolecular reactions and reactions with the carrier gas for dihydrogen atmosphere (argon was assumed to be chemically inert in thermal CVD). This is a reasonable approximation for CVD reactions in the gas phase at low precursor pressures and has been successfully applied in the past. ${ }^{13,15,16}$ It is common practice in computational studies to discuss reaction kinetics based on reaction barriers without explicit computation of the prefactors. The computational study is aiming at the gas phase chemistry and does not consider surface reactions. All possible reactions have been considered in a combinatorial fashion. If bior multimolecular reactions occur they can be highly exergonic; see the full reaction catalog given in the Supporting Information (Table SI-2). The decomposition reactions starting from TMB, which are thermodynamically allowed under the experimental conditions, i.e., unimolecular reactions with a negative Gibbs reaction energy at $T=1200{ }^{\circ} \mathrm{C}$ and an argon atmosphere, are shown in Scheme 1. The listed energies are for 
Scheme 1. Most Probable Gas Phase Reactions of TMB and Decomposition Products in an Argon Atmosphere ${ }^{a}$

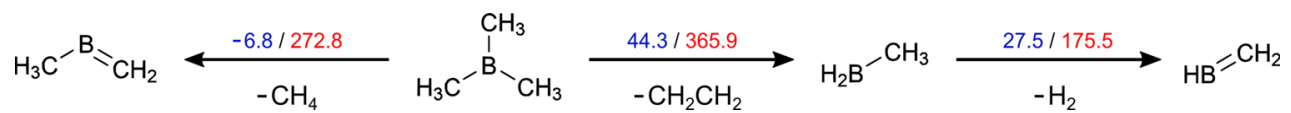

${ }^{a}$ Gibbs reaction energies $(\Delta G)$ and Gibbs activation energies $\left(\Delta G^{\dagger}\right)$ for CVD conditions $\left(T=800{ }^{\circ} \mathrm{C}, p=50 \mathrm{mbar}\right)$ in $\mathrm{kJ} / \mathrm{mol}(\mathrm{PBE} / \mathrm{def} 2-\mathrm{TZVPP})$.

$T=800{ }^{\circ} \mathrm{C}$, and reaction barriers were computed for thermodynamically allowed reactions only.

High energy barriers were shown for all decomposition reactions; however, the most likely pathway is abstraction of methane in a concerted fashion via an $\alpha$-H elimination reaction (Figure 7). A second possible pathway is the loss of ethane via a

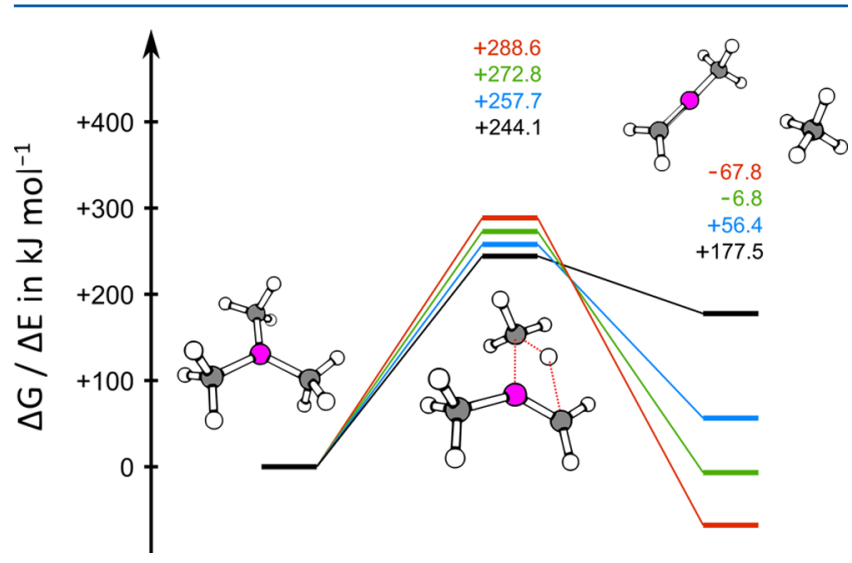

Figure 7. Decomposition of TMB via an $\alpha$-H elimination of methane to methylborane $\left(\mathrm{CH}_{2} \mathrm{BCH}_{3}\right)$. Reaction energies and barriers are color-coded: $\Delta E$, black; $\Delta G_{400}{ }^{\circ} \mathrm{C}$, blue; $\Delta G_{800}{ }^{\circ} \mathrm{C}$, green; $\Delta G_{1200}{ }^{\circ} \mathrm{C}$, red. two-step mechanism (Figure. SI-3) with quite high barriers. The resulting methylborane $\left(\mathrm{H}_{2} \mathrm{BCH}_{3}\right)$ can further decompose via loss of dihydrogen to $\mathrm{HBCH}_{2}$ (Figure SI-4). Further reactions exhibit high energy barriers or are strongly endergonic (Table SI-2).

The situation looks different under CVD conditions with dihydrogen as the carrier gas. In this case, reactions with dihydrogen must be considered as well. This leads to a larger network of energetically accessible reactions as shown in Scheme 2.

Unimolecular elimination of methane is still the decomposition pathway of TMB with the lowest energy barrier (Scheme 2, top arrow). However, the thermodynamic driving force for the alternative pathway via dihydogen-assisted methane elimination (Scheme 2, middle arrow) is considerably higher $\left(\Delta G_{800}{ }^{\circ} \mathrm{C}=-21.1 \mathrm{~kJ} \mathrm{~mol}^{-1}\right.$ vs $-6.8 \mathrm{~kJ} \mathrm{~mol}^{-1}$ without dihydrogen). This additional reaction channel could be an explanation for the experimental observation of higher CVD decomposition rates in a dihydrogen atmosphere at lower deposition temperatures (Figure 2). Furthermore, the dihydrogen-assisted methane elimination of $\mathrm{H}_{3} \mathrm{CBCH}_{2}$ to $\mathrm{HBCH}_{2}$ also exhibits a much lower barrier and is thermodynamically favored in comparison to the unimolecular pathway, making $\mathrm{BHCH}_{2}$ a probable film-forming species in a dihydrogen ambient.

Scheme 2. Most Probable Gas Phase Reactions of TMB and Decomposition Products in Dihydrogen Atmosphere ${ }^{a}$

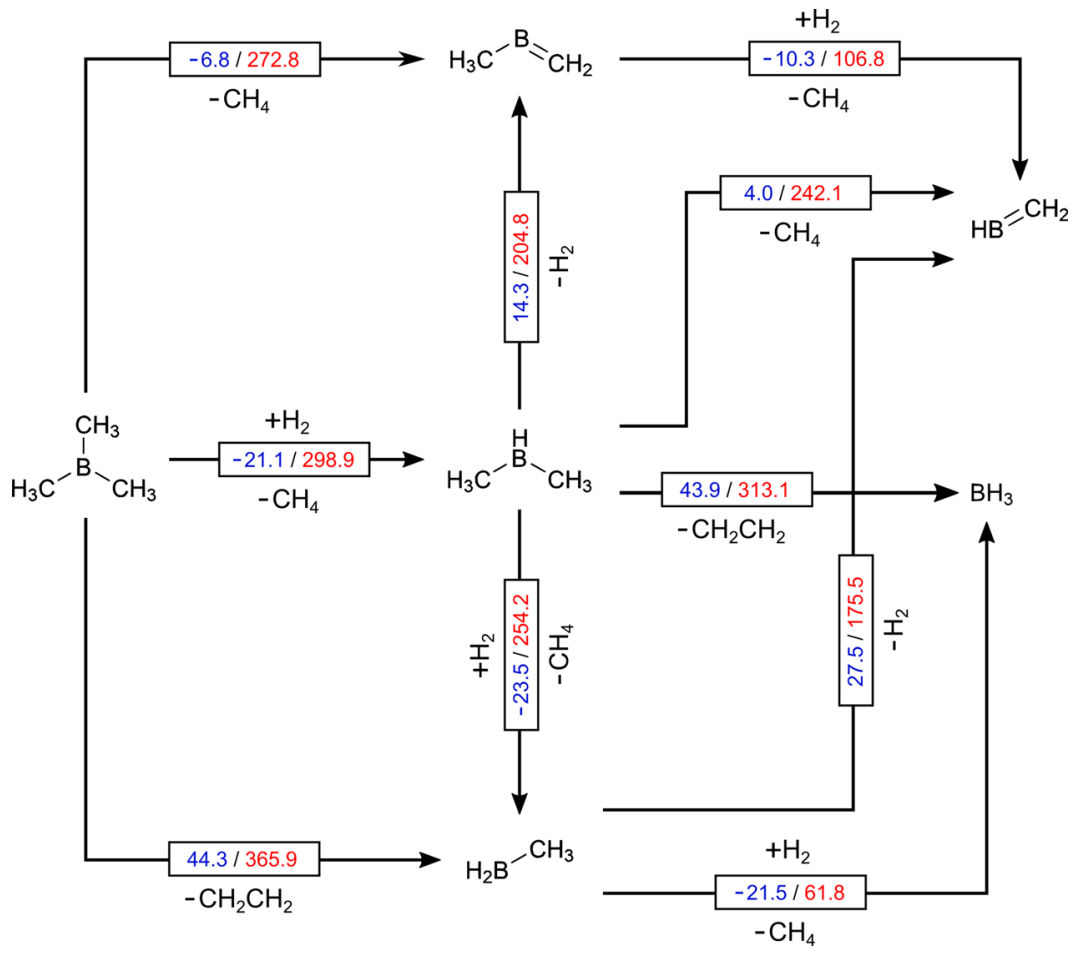

${ }^{a}$ Gibbs reaction energies $(\Delta G)$ and Gibbs activation energies $\left(\Delta G^{\dagger}\right)$ for CVD conditions $\left(T=800{ }^{\circ} \mathrm{C}, p=50 \mathrm{mbar}\right) \mathrm{in} \mathrm{kJ} / \mathrm{mol}(\mathrm{PBE} / \mathrm{def} 2-\mathrm{TZVPP})$. 
The homolytic dissociation reactions generally show much less favorable thermodynamic characteristics (Table SI-2), which was previously also found for TEB. ${ }^{13}$ This is also in line with the endergonic reactions observed for methyl radical abstraction of trimethylgallium (TMGa) in the past. ${ }^{27}$ Even if only a very small concentration of radical species is formed, these will strongly react with the surface and other fragments to initiate film formation.

Gas Phase CVD Chemistry of TMB. Without assistance from the carrier gas, i.e., in argon ambient, TMB decomposes most likely by elimination of methane to form $\mathrm{H}_{2} \mathrm{CBCH}_{3}$ (Scheme 1). Methane is not very reactive in CVD at the low deposition temperatures investigated, suggesting that $\mathrm{H}_{2} \mathrm{CBCH}_{3}$ is the major film-forming species. This correlates with the $\mathrm{B} / \mathrm{C}$ ratio of 0.5 , which was observed for films deposited in argon at $700-900{ }^{\circ} \mathrm{C}$ (Figure 3). At higher temperatures, the $\mathrm{B} / \mathrm{C}$ ratio increases to 1.5 at $1000{ }^{\circ} \mathrm{C}$ and 1.25 at $1100{ }^{\circ} \mathrm{C}$. This is attributed to an elevated degree of decomposition to $\mathrm{H}_{2} \mathrm{BCH}_{3}$ at temperatures $>900{ }^{\circ} \mathrm{C}$ and is most likely accompanied by some hydrocarbon-eliminating surface chemistry to render a B/C $>1$. The drop in $\mathrm{B} / \mathrm{C}$ at $1100{ }^{\circ} \mathrm{C}$ compared to $1000{ }^{\circ} \mathrm{C}$ can be explained by an increased CVD activity of methane at the higher temperature, allowing methane to deposit carbon onto the film.

With assistance from the hydrogen carrier gas, TMB can first decompose to $\mathrm{HB}\left(\mathrm{CH}_{3}\right)_{2}$, followed by $\mathrm{H}_{2} \mathrm{BCH}_{3}$ and then to $\mathrm{BH}_{3}$. All decomposition steps have negative Gibbs free energies, albeit some showing high energy barriers (Scheme 2). This pathway, in combination with the unimolecular elimination of methane to form $\mathrm{H}_{2} \mathrm{CBCH}_{3}$-a $26.1 \mathrm{~kJ} / \mathrm{mol}$ lower energy barrier (272.8 vs $298.9 \mathrm{~kJ} / \mathrm{mol}$ ) — can explain the higher B/C ratios for films deposited in dihydrogen (Figure 3 ). At low temperatures the pathway with the lowest energy barrier is expected to dominate, forming $\mathrm{H}_{2} \mathrm{CBCH}_{3}$ and rendering films with low $\mathrm{B} / \mathrm{C}$ ratios. However, since the $\mathrm{B} / \mathrm{C}$ ratios of films deposited in dihydrogen are higher compared to corresponding films deposited in argon, the decomposition pathway to species which give a higher $\mathrm{B} / \mathrm{C}$ ratio, $\mathrm{H}_{2} \mathrm{BCH}_{3}$ and $\mathrm{BH}_{3}$, are still active. The higher the deposition temperature, the higher the contribution from the dihydrogen-assisted elimination to $\mathrm{HB}\left(\mathrm{CH}_{3}\right)_{2}$. This increases the concentration of $\mathrm{H}_{2} \mathrm{BCH}_{3}$ and $\mathrm{BH}_{3}$ in the gas phase and allows for films with a higher $\mathrm{B} / \mathrm{C}$ ratio to be deposited (Figure 3). The decrease in B/C at 1100 ${ }^{\circ} \mathrm{C}$, also in films deposited in dihydrogen, is assigned to the increased CVD activity of methane at higher temperatures.

\section{CONCLUSION}

In conclusion, we found that the gas phase CVD chemistry of TMB is dominated by a unimolecular $\alpha-\mathrm{H}$ elimination of methane to form $\mathrm{H}_{2} \mathrm{CBCH}_{3}$ in an inert argon carrier gas. At low temperatures between 700 and $900{ }^{\circ} \mathrm{C}$, films with a B/C ratio of 0.5 were formed when TMB is used as a single-source CVD precursor in argon. Further decomposition of $\mathrm{H}_{2} \mathrm{CBCH}_{3}$ to $\mathrm{H}_{2} \mathrm{BCH}_{3}$ is expected at deposition temperatures $>900{ }^{\circ} \mathrm{C}$, which leads to higher $\mathrm{B} / \mathrm{C}$ ratios in the films. In a dihydrogen atmosphere, a bimolecular decomposition route to $\mathrm{HB}\left(\mathrm{CH}_{3}\right)_{2}$ is also available, albeit with a higher energy barrier. The $\mathrm{HB}\left(\mathrm{CH}_{3}\right)_{2}$ species can further decompose to $\mathrm{H}_{2} \mathrm{BCH}_{3}$ and then $\mathrm{BH}_{3}$, which could explain the higher $\mathrm{B} / \mathrm{C}$ ratio for films deposited in dihydrogen compared to films deposited in argon.

\section{ASSOCIATED CONTENT}

\section{Supporting Information}

The Supporting Information is available free of charge on the ACS Publications website at DOI: 10.1021/acs.jpcc.7b09538.

Film density measurements; additional XRD diffractograms; quantum-chemical calculations; the automatization scheme used for the computation (PDF)

\section{AUTHOR INFORMATION}

\section{Corresponding Author}

*E-mail: henrik.pedersen@liu.se. Twitter: @hacp81.

ORCID $\odot$

Richard Hall-Wilton: 0000-0003-3221-2086

Jens Birch: 0000-0002-8469-5983

Ralf Tonner: 0000-0002-6759-8559

Henrik Pedersen: 0000-0002-7171-5383

\section{Notes}

The authors declare no competing financial interest.

\section{ACKNOWLEDGMENTS}

Financial support from European Spallation Source ERIC, the Knut and Alice Wallenberg Foundation, and the German Science Foundation (GRK 1782) is gratefully acknowledged. L.S. acknowledges financial support from The Swedish Foundation for Strategic Research (SSF) and contract IS140027. H.P. and R.T. are very grateful for the networking support provided from COST Action MP1402 Hooking together European research in atomic layer deposition (HERALD), supported by COST (European Cooperation in Science and Technology). H.H. acknowledges financial support from the Swedish Government Strategic Research Area in Materials Science on Functional Materials at Linköping University (Faculty Grant SFO-Mat-LiU No. 2009-00971). The authors also acknowledge the Tandem Laboratory at Uppsala University for giving access to their ion beam facilities and Nathan O'Brien for critically reading the manuscript. We thank HRZ Marburg, LOEWE-CSC Frankfurt and HLR Stuttgart for providing computational resources.

\section{REFERENCES}

(1) Deshpande, S. V.; Gulari, E.; Harris, S. J.; Weiner, A. M. Filament Activated Chemical Vapor Deposition of Boron Carbide Coatings. Appl. Phys. Lett. 1994, 65, 1757-1759.

(2) Oliveira, J. C.; Oliveira, M. N.; Conde, O. Structural Characterisation of $\mathrm{B}_{4} \mathrm{C}$ Films Deposited by Laser-Assisted CVD. Surf. Coat. Technol. 1996, 80, 100-104.

(3) Pallier, C.; Leyssale, J.-M.; Truflandier, L. A.; Bui, A. T.; Weisbecker, P.; Gervais, C.; Fischer, H. E.; Sirotti, F.; Teyssandier, F.; Chollon, G. Structure of an Amorphous Boron Carbide Film: An Experimental and Computational Approach. Chem. Mater. 2013, 25, 2618-2629.

(4) Künzle, H.; Gantenbein, P.; Steiner, R.; Oelhafen, P. Deposition and Characterization of Thin Boron-Carbide Coatings. Fresenius' J. Anal. Chem. 1993, 346, 41-44.

(5) Andujar, J. L.; Bertran, E.; Polo, M. C. Plasma-Enhanced Chemical Vapor Deposition of Boron Nitride Thin Films from $\mathrm{B}_{2} \mathrm{H}_{6}-$ $\mathrm{H}_{2}-\mathrm{NH}_{3}$ and $\mathrm{B}_{2} \mathrm{H}_{6}-\mathrm{N}_{2}$ Gas Mixtures. J. Vac. Sci. Technol., A 1998, 16, 578-586.

(6) Pierson, H. O.; Mullendore, A. W. The Chemical Vapor Deposition of $\mathrm{TiB}_{2}$ From Diborane. Thin Solid Films 1980, 72, 511516. 
(7) Beckloff, B. N.; Lackey, W. J. Process-Structure-Reflectance Correlations for $\mathrm{TiB}_{2}$ Films Prepared by Chemical Vapor Deposition. J. Am. Ceram. Soc. 1999, 82, 503-512.

(8) Cholet, V.; Herbin, R.; Vandenbulcke, L. Chemical Vapour Deposition of Boron Carbide From $\mathrm{BBr}_{3}-\mathrm{CH}_{4}-\mathrm{H}_{2}$ Mixtures in a Microwave Plasma. Thin Solid Films 1990, 188, 143-155.

(9) Dekker, J. P.; van der Put, P. J.; Veringa, H. J.; Schoonman, J. Chemical Vapour Infiltration of TiB2 and $\mathrm{TiN}$ in Porous $\mathrm{Al}_{2} \mathrm{O}_{3}$. J. Eur. Ceram. Soc. 1994, 14, 245-255.

(10) Lewis, J. S.; Vaidyaraman, S.; Lackey, W. J.; Agrawal, P. K.; Freeman, G. B.; Barefield, E. K. Chemical Vapor Deposition of BoronCarbon Thin Films using Organometallic Reagents. Mater. Lett. 1996, 27, 327-332.

(11) Chubarov, M.; Pedersen, H.; Högberg, H.; Czigány, Zs.; Garbrecht, M.; Henry, A. Polytype Pure $\mathrm{sp}^{2}-\mathrm{BN}$ Thin Films As Dictated by the Substrate Crystal Structure. Chem. Mater. 2015, 27, 1640-1645.

(12) Pedersen, H.; Höglund, C.; Birch, J.; Jensen, J.; Henry, A. Low Temperature CVD of Thin, Amorphous Boron-Carbon Films for Neutron Detectors. Chem. Vap. Deposition 2012, 18, 221-224.

(13) Imam, M.; Gaul, K.; Stegmüller, A.; Höglund, C.; Jensen, J.; Hultman, L.; Birch, J.; Tonner, R.; Pedersen, H. Gas Phase Chemical Vapor Deposition Chemistry of Triethylboron Probed by BoronCarbon Thin Film Deposition and Quantum Chemical Calculations. J. Mater. Chem. C 2015, 3, 10898-10906.

(14) Imam, M.; Höglund, C.; Jensen, J.; Schmidt, S.; Ivanov, I. G.; Hall-Wilton, R.; Birch, J.; Pedersen, H. Trimethylboron as SingleSource Precursor for Boron-Carbon Thin Film Synthesis by Plasma Chemical Vapor Deposition. J. Phys. Chem. C 2016, 120, 2199021997.

(15) Sterzer, E.; Beyer, A.; Duschek, L.; Nattermann, L.; Ringler, B.; Leube, B.; Stegmüller, A.; Tonner, R.; von Hänisch, C.; Stolz, W.; et al. Efficient Nitrogen Incorporation in GaAs Using Novel Metal Organic As-N Precursor Di-Tertiary-Butyl-Arsano-Amine (DTBAA). J. Cryst. Growth 2016, 439, 19-27.

(16) Stegmüller, A.; Rosenow, P.; Tonner, R. A Quantum Chemical Study on Gas Phase Decomposition Pathways of Triethylgallane (TEG, $\left.\mathrm{Ga}\left(\mathrm{C}_{2} \mathrm{H}_{5}\right)_{3}\right)$ and Tert-Butylphosphine (TBP, $\mathrm{PH}_{2}\left(t-\mathrm{C}_{4} \mathrm{H}_{9}\right)$ ) under MOVPE Conditions. Phys. Chem. Chem. Phys. 2014, 16, 1701817029.

(17) Scheubert, K.; Hufsky, F.; Bocker, S. Computational Mass Spectrometry for Small Molecules. J. Cheminf. 2013, 5, 12.

(18) Bauer, C. A.; Grimme, S. How to Compute Electron Ionization Mass Spectra from First Principles. J. Phys. Chem. A 2016, 120, 37553766.

(19) Husch, T.; Korth, M. How to Estimate Solid-ElectrolyteInterphase Features When Screening Electrolyte Materials. Phys. Chem. Chem. Phys. 2015, 17, 22799-22808.

(20) Perdew, J.; Burke, K.; Ernzerhof, M. Generalized Gradient Approximation Made Simple. Phys. Rev. Lett. 1996, 77, 3865-3868.

(21) Weigend, F.; Ahlrichs, R. Balanced Basis Sets of Split Valence, Triple Zeta Valence and Quadruple Zeta Valence Quality for H to Rn: Design and Assessment of Accuracy. Phys. Chem. Chem. Phys. 2005, 7, 3297-3305.

(22) Peng, C.; Ayala, P.; Schlegel, H. B.; Frisch, M. J. Using Redundant Internal Coordinates to Optimize Equilibrium Geometries and Transition States. J. Comput. Chem. 1996, 17, 49-56.

(23) Hratchian, H. P.; Schlegel, H. B. Using Hessian Updating to Increase the Efficiency of a Hessian Based Predictor-Corrector Reaction Path Following Method. J. Chem. Theory Comput. 2005, 1, 61-69.

(24) Frisch, M. J.; Trucks, G. W.; Schlegel, H. B.; Scuseria, G. E.; Robb, M. A.; Cheeseman, J. R.; Scalmani, G.; Barone, V.; Mennucci, B.; Petersson, G. A.; et al. Gaussian 09; Gaussian, Inc.: Wallingford, CT, 2009.

(25) Wei, B.; Vajtai, R.; Jung, Y. J.; Banhart, F.; Ramanath, G.; Ajayan, P. M. Massive Icosahedral Boron Carbide Crystals. J. Phys. Chem. B 2002, 106, 5807-5809.
(26) Bao, R.; Chrisey, D. B. Chemical States of Carbon in Amorphous Boron Carbide Thin Films Deposited by Radio Frequency Magnetron Sputtering. Thin Solid Films 2010, 519, 164-168.

(27) Schmid, R.; Basting, D. Gas Phase Chemistry in Gallium Nitride CVD: Theoretical Determination of the Arrhenius Parameters for the First Ga-C Bond Homolysis of Trimethylgallium. J. Phys. Chem. A 2005, 109, 2623-2630. 